\title{
REVIEW \\ Neuropathic pain and spasticity: intricate consequences of spinal cord injury
}

\author{
NB Finnerup
}

Study design: The 2016 International Spinal Cord Society Sir Ludwig Guttmann Lecture.

Objectives: The aim of this review is to identify different symptoms and signs of neuropathic pain and spasticity after spinal cord injury (SCl) and to present different methods of assessing them. The objective is to discuss how a careful characterization of different symptoms and signs, and a better translation of preclinical findings may improve our understanding of the complex and entangled mechanisms of neuropathic pain and spasticity.

Methods: A MEDLINE search was performed using the following terms: 'pain', 'neuropathic', 'spasticity', 'spasms' and 'spinal cord injury'. Results: This review identified different domains of neuropathic pain and spasticity after SCl and methods to assess them in preclinical and clinical research. Different factors important for pain description include location, onset, pain descriptors and somatosensory function, while muscle tone, spasms, reflexes and clonus are important aspects of spasticity. Similarities and differences between neuropathic pain and spasticity are discussed.

Conclusions: Understanding that neuropathic pain and spasticity are multidimensional consequences of SCl, and a careful examination and characterization of the symptoms and signs, are a prerequisite for understanding the relationship between neuropathic pain and spasticity and the intricate underlying mechanisms.

Spinal Cord (2017) 55, 1046-1050; doi:10.1038/sc.2017.70; published online 11 July 2017

\section{INTRODUCTION}

This review discusses the need for a phenotype-based classification of both neuropathic pain and spasticity in order to understand the common and diverse mechanisms of these intertwined consequences of SCI.

Following SCI, neuroplasticity, which involves both neuronal, structural and functional responses, is essential for recovery of the neurological function, but the dark side of this neuroplasticity can be the development of neuropathic pain and spasticity. ${ }^{1}$ These common disabling conditions negatively affect mood, sleep, quality of life, and participation in activities and active recreation as well as employment. ${ }^{2-7}$ Neuropathic pain is present in $50-60 \%$ and spasticity in about $70 \%$ of individuals living with a SCI. ${ }^{5,8-11}$

Neuropathic pain is a multidimensional constellation of phenomenologically different symptoms and is defined as 'pain caused by a lesion or disease of the somatosensory nervous system'. ${ }^{12,13}$ Neuropathic pain following SCI includes at- and below-level SCI neuropathic pain, where at-level pain may consist of both peripheral and central neuropathic pain, while below-level pain is a central neuropathic pain condition. ${ }^{14}$ The pain may be spontaneous and described as burning, squeezing, shooting or pricking pain, and/or evoked (allodynia and hyperalgesia), which is most commonly evoked by touch and cold stimuli. Clinically, it may be difficult to distinguish neuropathic pain from other types of pain such as musculoskeletal pain, which is common after SCI, due to, for example, spasms, contractures and overuse.
Spasticity is also a multidimensional constellation of phenomenologically diverse symptoms and has been defined as 'a disordered sensorimotor control resulting from an upper motor neuron lesion, presenting as intermittent or sustained involuntary activation of muscles', ${ }^{15}$ and this broad definition of spasticity is adopted in the spinal cord injury musculoskeletal data set. ${ }^{16}$ This definition includes velocity-dependent increase in tonic stretch reflexes (muscle tone) and phasic stretch reflexes (exaggerated tendon jerks) that formed the original definition of spasticity, ${ }^{17}$ as well as flexor- and extensor spasms, flexor reflexes, and altered motor control. Clinically, it is often difficult to separate spasticity from symptoms and signs caused by structural changes in the muscles. ${ }^{18}$

The aim of this review is to present different domains of neuropathic pain and spasticity with possible different underlying mechanisms and to discuss the assessment of these in preclinical and clinical research. The hope is that a more elaborate classification will improve the translation of preclinical studies to the clinic and understanding of the complex and entangled mechanisms of neuropathic pain and spasticity.

\section{NEUROPATHIC PAIN AND SPASTICITY: TWO SIDES OF THE SAME COIN?}

Central neuropathic pain shares many features with spasticity and has even been termed 'sensory spasticity'. ${ }^{19}$ Both pain and spasticity can have a late onset and develop slowly over time after SCI, and once developed, they often become chronic. In addition, both conditions 
Table 1 Different domains in neuropathic pain and their assessment in human and animal research

\begin{tabular}{|c|c|c|}
\hline Domain & Clinical assessment & Preclinical assessment \\
\hline Ongoing pain & $\begin{array}{l}\text { - Numeric rating scale } \\
\text { - Visual analog scale }\end{array}$ & $\begin{array}{l}\text { - Conditioned place- } \\
\text { preference paradigms }\end{array}$ \\
\hline $\begin{array}{l}\text { Evoked pain } \\
\text { Thermal gain } \\
\text { Mechanical gain }\end{array}$ & $\begin{array}{l}\text { Pain intensity to: } \\
\text { - Thermal stimulation } \\
\text { (for example, thermal } \\
\text { rollers, acetone droplet, } \\
\text { thermal testing) } \\
\text { - Mechanical stimulation } \\
\text { (for example } \\
\text { monofilaments, cotton, } \\
\text { brush) }\end{array}$ & $\begin{array}{l}\text { Supraspinal responses to: } \\
\text { - Thermal stimulation } \\
\text { (e.g. cold plate, } \\
\text { acetone droplet, } \\
\text { radiant heat) } \\
\text { - Mechanical stimulation } \\
\text { (e.g. monofilaments, } \\
\text { cotton, brush) }\end{array}$ \\
\hline $\begin{array}{l}\text { Somatosensory function } \\
\text { Thermal loss } \\
\text { Mechanical loss }\end{array}$ & $\begin{array}{l}\text { Sensory testing to } \\
\text { thermal and } \\
\text { mechanical stimuli }\end{array}$ & $\begin{array}{l}\text { Supraspinal responses to } \\
\text { thermal and mechanical } \\
\text { stimuli }\end{array}$ \\
\hline Onset of pain & $\begin{array}{l}\text { - Early (within weeks) } \\
\text { - Late (within months) }\end{array}$ & $\begin{array}{l}\text { - Early (within days) } \\
\text { - Late (within weeks) }\end{array}$ \\
\hline Location & $\begin{array}{l}\text { Location of pain and } \\
\text { sensory loss and gain } \\
\text { - At-level } \\
\text { - Below-level }\end{array}$ & $\begin{array}{l}\text { Location of sensory } \\
\text { loss and gain } \\
\text { - At-level } \\
\text { - Below-level }\end{array}$ \\
\hline $\begin{array}{l}\text { Pain quality } \\
\text { Burning pain } \\
\text { Pressing/squeezing } \\
\text { Paroxysmal pain } \\
\text { Pricking pain/pins } \\
\text { and needles } \\
\text { Evoked pain }\end{array}$ & $\begin{array}{l}\text { Pain questionnaires, } \\
\text { for example: } \\
\text { - Neuropathic pain } \\
\text { symptom inventory } \\
\text { - Pain Quality } \\
\text { Assessment } \\
\text { Scale }\end{array}$ & NA \\
\hline $\begin{array}{l}\text { Other domains } \\
\text { Anxiety/depression } \\
\text { Pain impact } \\
\text { Pain catastrophizing } \\
\text { Participation }\end{array}$ & $\begin{array}{l}\text { Questionnaires or } \\
\text { interview }\end{array}$ & $\begin{array}{l}\text { Behavioral tests, for } \\
\text { example, } \\
\text { - Thigmotaxis paradigm } \\
\text { - Elevated-plus maze } \\
\text { - Burrowing }\end{array}$ \\
\hline
\end{tabular}

may be elicited by touch and other non-painful stimulation. Gabapentin and pregabalin, which are classic drugs used in the treatment of neuropathic pain, are suggested also to have an effect on spasticity. ${ }^{20,21}$ Similarly, $\mathrm{GABA}_{\mathrm{A}}$ receptor agonists, which are sometimes used for spasticity in the form of benzodiazepines, are also suggested to have an effect on central pain and central sensitization, maybe particularly on allodynia and hyperalgesia. ${ }^{22,23} \mathrm{On}$ the other hand, central pain and spasticity may develop independently, the tricyclic antidepressant amitriptyline, which is also a first-line drug for neuropathic pain, ${ }^{24}$ is suggested to increase spasticity, ${ }^{25}$ and the most commonly used drug for spasticity, baclofen, has no proven effect in neuropathic pain. So there seem to be both similarities and differences.

It is difficult to examine possible relationships between neuropathic pain and spasticity due to the difficulty in distinguishing neuropathic pain from musculoskeletal pain, which is a very common result of spasticity. ${ }^{26}$ Certain pain types are particularly difficult to classify, for example, the characteristic squeezing and pressing type of pain. In addition, the frequent use of drugs for spasticity and pain likely affects the severity of spasticity and pain in individual patients, which may blur a possible correlation between the severity of the untreated symptoms. Furthermore, the failure to differentiate between different phenotypes of pain and spasticity may prevent us from identifying similarities. In a questionnaire study based solely on patient-reported outcomes, the presence of pain was related to the presence of spasticity and a higher intensity rating of muscle stiffness, while only pain with typical neuropathic pain descriptors was related to the frequency of spasms. ${ }^{5}$ This suggests that different subtypes of pain and spasticity may be related. The multidimensional nature of pain and spasticity calls for the use of different scales to measure various aspects of spasticity ${ }^{27,28}$ and pain, ${ }^{29,30}$ and these will be discussed in the following sections.

\section{MULTIDIMENSIONAL ASSESSMENT OF PAIN}

For neuropathic pain, there is now good evidence from clinical research to suggest that at-level and below-level pain are two different pain types. Below-level pain often develops months later than at-level pain, and sensory hypersensitivity is a predictor of below-level but not at-level pain. ${ }^{8,31}$ However, hypersensitivity is not always present early on in patients who develop below-level pain, ${ }^{31,32}$ and within both below-level and at-level pain, there likely are different pain phenotypes with different constellations of sensory descriptors and sensory signs that may reflect different underlying mechanisms and possible different responses to treatment. For example, within both central and peripheral neuropathic pain, five distinct dimensions have been identified based on neuropathic pain descriptors, that is, burning pain, squeezing pain, paroxysmal pain, evoked pain, and pins and needles sensations. ${ }^{33}$ Using cluster analysis of the results of quantitative sensory testing, three different clusters have also been identified based on sensory profiles, which are as follows: (1) a cluster characterized by loss of small and large fiber function; (2) a cluster characterized by relatively preserved large and small fiber sensory functions in combination with thermal hyperalgesia and (3) a cluster characterized by thermal sensory loss and mechanical allodynia and hyperalgesia. ${ }^{34}$ Psychological factors such as anxiety and depression, pain catastrophizing, and adaptive pain coping are also important factors in the multidimensional neuropathic pain description. ${ }^{35,36}$ Evidence is now beginning to emerge supporting that such phenotype-based classifications are related to pain mechanisms and that they may have treatment implications. ${ }^{29,37}$ Sodium channel blockers are, for example, suggested to be more effective in patients with preserved pain and thermal sensation than in patients who have mainly sensory loss. ${ }^{38,39}$ Some of the factors relevant for characterizing neuropathic pain in clinical research are listed in Table 1 and are also recommended in the International SCI Pain Extended Data Set. ${ }^{40}$

Several SCI models are used in preclinical research, including hemisection, contusion, ischemic and excitotoxic models, but pain assessment remains a challenge. One of the main reasons is the difficulty in assessing the correlate of spontaneous pain, which is the most frequent and troublesome pain symptom in humans. ${ }^{41,42}$ Conditioned place-preference paradigms, which are standard preclinical behavioral models used to demonstrate the reward of analgesic drugs, have been used in SCI models. ${ }^{43}$ The models are used to assess the presence of tonic pain by, for example, examining the rats' preference for environments that has previously been paired with analgesics or not. Burrowing, which is an ethologically relevant rodent behavior, has recently been used as an indication of behavioral dysfunction and has shown some degree of predictive validity as an outcome measure for pain. ${ }^{44}$ Psychological domains can also be assessed using, for example, the thigmotaxis paradigm in the openfield test, the elevated plus maze for assessment of anxiety-like behavior, or the forced swimming test for depression-like behavior. ${ }^{45}$ Like in humans, evoked responses to pinprick, dynamic 
Table 2 Different domains of spasticity and their assessment in human and animal research

\begin{tabular}{|c|c|c|}
\hline Domain & Clinical assessment & Preclinical assessment \\
\hline Muscle spasms & $\begin{array}{l}\text { - Penn Spasm } \\
\text { - Srequency Scale } \\
\text { - Spasm frequency score } \\
\text { - Spasm severity scale } \\
\text { - The Spinal Cord } \\
\text { - Assessment } \\
\text { - Tool for Spastic Reflexes }\end{array}$ & $\begin{array}{l}\text { - Twitches } \\
\text { - Frequency and severity } \\
\text { of spasms e.g. during } \\
\text { swimming } \\
\text { - Withdrawal reflexes to } \\
\text { mechanical or thermal } \\
\text { stimuli } \\
\text { - EMG during withdrawal }\end{array}$ \\
\hline $\begin{array}{l}\text { Velocity-dependent } \\
\text { increase in resistance } \\
\text { to passive movement }\end{array}$ & $\begin{array}{l}\text { - Intensity rating of } \\
\text { - } \text { muscle stiffness } \\
\text { - Modified ashworth scale } \\
\text { - Modified tardieu scale } \\
\text { - EMG activity to stretch } \\
\text { - Wartenberg pendulum } \\
\text { test }\end{array}$ & $\begin{array}{l}\text { - Velocity-dependent } \\
\text { changes in resistance } \\
\text { during flexion } \\
\text { - Tail resistance to stretch } \\
\text { - EMG activity to stretch }\end{array}$ \\
\hline Increased tendon reflexes & $\begin{array}{l}\text { - Deep tendon reflexes } \\
\text { - T-reflex }\end{array}$ & - T-reflex \\
\hline Clonus & $\begin{array}{l}\text { - Clonus score } \\
\text { - The Spinal Cord } \\
\text { Assessment } \\
\text { - Tool for Spastic Reflexes }\end{array}$ & $\begin{array}{l}\text { - Quantification of repeated } \\
\text { muscle jerks e.g. of the } \\
\text { tail or during onset of } \\
\text { stance }\end{array}$ \\
\hline $\begin{array}{l}\text { Dyssynergic pattern of } \\
\text { co-contraction during } \\
\text { walking }\end{array}$ & $\begin{array}{l}\text { - Gait and movement } \\
\text { analyses }\end{array}$ & $\begin{array}{l}\text { - Dynamic } \\
\text { electromyograms } \\
\text { - Assessment of } \\
\text { movements }\end{array}$ \\
\hline
\end{tabular}

stimulation using a brush, and cold stimuli using acetone droplets, or thermally regulated plates can be assessed, ${ }^{46,47}$ but the assessment of stimulus-evoked pain-like behavior poses specific problems in models of central pain. These often rely on simple spinally mediated withdrawal reflexes, which are present after spinal transection and may be increased as part of the development of spasticity. It has been shown that motor and projection neurons in the pain pathways are affected differently by SCI and that withdrawal reflexes do not always reflect pain-like hypersensitivity. ${ }^{41,46,48-50}$ Methods that depend on cortical processing such as operant escape testing and the place escape/ avoidance paradigm or at least are dependent on the brain stem (for example, licking, guarding and vocalizing) are needed, but it is important to keep in mind that the neural circuits subserving vocalization reflexes and conscious appreciation of nociceptive intensity also can react differently to SCI. ${ }^{46-48,50}$ Examples of assessment methods of different neuropathic pain subtypes in preclinical research are listed in Table 1.

\section{MULTIDIMENSIONAL ASSESSMENT OF SPASTICITY}

The multidimensional nature of spasticity with various distinct presentations also calls for the use of different instruments to measure the various clinical presentations. ${ }^{27,28,51}$ The different components of spasticity are likely to have different underlying mechanisms. For example, increased muscle tone and exaggerated tendon reflexes can occur after central nervous system lesions at all levels, while exaggerated flexion and withdrawal reflexes are seen after spinal lesions, and modulatory effects of descending reticulospinal pathways in the dorsolateral column can have opposite effects on stretch and flexion reflexes. ${ }^{52}$

The most commonly used clinical instruments to measure muscle tone are the Ashworth Scale, ${ }^{53}$ the Modified Ashworth Scale ${ }^{54}$ and the Modified Tardieu Scale. ${ }^{55}$ Spasm scales include the Penn Spasm Frequency Scale ${ }^{56}$ and the spasm frequency score. ${ }^{27}$ The Spinal Cord Assessment Tool for Spastic Reflexes evaluates three distinct types of motor behavior: clonus, flexor spasms and extensor spasms. ${ }^{57}$ Clonus in response to a rapid passive dorsiflexion of the ankle is rated based on the time clonus is maintained, severity of flexor spasms is rated based on the response to a pinprick stimulus applied to the plantar foot, and extensor spasms based on the duration of visible muscle contractions to hip and knee extension. ${ }^{57}$ Electrophysiological measures include electromyography (EMG) responses to electrical stimuli such as the Hoffmann reflex (H-reflex), the F-wave, the flexor reflex or tendon percussion (the tendon reflex, T-reflex), but they do not directly correlate with clinical signs. ${ }^{58}$ In addition, different gait and movement analyses can be made. The different modalities of spasticity and examples of assessment methods are presented in Table 2.

Similar to the situation with pain, it is challenging to assess the different types of spastic motor behaviors in rodents (Table 2). ${ }^{59}$ Different methods have been developed to assess muscle resistance to stretch at different velocities in the limb or tail, including a computercontrolled ankle rotational system, ${ }^{60}$ a handheld strain gauge, ${ }^{61}$ a digital resistance transducer ${ }^{62}$ and measurement of EMG responses. As mentioned above, stimulus-evoked paw withdrawal thresholds do not correlate with hypersensitivity, but they also do not seem to correlate with increased muscle tone, and are suggested to reflect hyperreflexia with pathophysiological analogs of spasms or clonus. ${ }^{50}$ The evaluation of stimulus-evoked paw withdrawal can be compared to the evaluation of flexor spasms in the Spinal Cord Assessment Tool for Spastic Reflexes. Similarly, tail flick to pinch or radiant heat can be used for evaluation of withdrawal tresholds. ${ }^{63}$ Quantitative and qualitative assessment of hindlimb and tail spasms during swimming has also been used to assess spasms. ${ }^{64}$ Co-contraction patterns of antagonistic muscles can be assessed using, for example, dynamic electromyograms of muscle contractions during bipedal gait, ${ }^{61}$ and detailed analysis of joint movements may identify various signs of spasticity. ${ }^{65}$

\section{IDENTIFYING MECHANISMS THAT NEUROPATHIC PAIN AND SPASTICITY HAVE IN COMMON}

Neuropathic pain and spasticity are not caused by simple mechanisms, but involve a complex chain of alterations in various interdependent networks. ${ }^{18,66,67}$ Proposed mechanisms of both neuropathic pain and spasticity involve disinhibition from loss of descending pathways or interneurons, neuronal hyperexcitability, ectopic firing, sprouting, receptor upregulation, deafferentation effects on rostral or caudal neurons, glia activation and neuroinflammation, although the neuronal circuits involved in neuropathic pain and spasticity are likely to differ-at least to some extent. ${ }^{60,67}$ The multidimensional nature of neuropathic pain and spasticity is important to consider when studying the underlying mechanisms or assessing treatment effects in both preclinical and clinical research, since the different symptoms and signs of neuropathic pain and spasticity can exist independently and do not necessarily have common underlying mechanisms or treatment responses. ${ }^{18,29}$

Most clinical and preclinical research has focused on either pain or spasticity, while few studies have investigated both conditions at the same time. One exception is a series of studies carried out by 




Figure $1 \mathrm{~A}$ simplified schematic representation of how lesions and hyperexcitability in different pathways may be involved in generating various symptoms and signs of neuropathic pain and spasticity. The grey lines indicate the spinal cord, the dark grey area the injury site, and the dashed lines interrupted axons. For details, please see the text. Adapted from Vierck et al. ${ }^{52}$

Vierck and colleagues more than 15 years ago. On the basis of extensive animal studies, ${ }^{68,69}$ they suggested that exaggerated flexion and withdrawal reflexes as well as below-level pain result from a combination of long tract damage and abnormal activity in the spinal grey matter as well as a facilitatory role of propriospinal systems, albeit with different circuits involved (Figure 1).$^{52}$ In this model, exaggerated withdrawal reflexes result from disrupted descending reticulospinal pathways and spread of neuronal hyperexcitability to motoneurons, whereas allodynia and hyperalgesia and possibly also ongoing below-level pain are suggested to result from facilitatory effects on partially preserved spinothalamic tract neurons. Ongoing below-level pain in patients with a complete lesion is proposed to involve effects on deafferented supraspinal neurons in the pain pathways. This theory is supported by studies finding a correlation between evoked at-level pain and ongoing below-level pain. ${ }^{70-72}$ Further studies that carefully assess various symptoms of SCI and their changes over time and a better understanding of the translation of behavioral correlates of pain and spasticity from animals to humans and back are needed in order to further understand how various changes in interdependent neuronal networks can result in different symptoms and signs.

\section{CONCLUSIONS}

Neuropathic pain and spasticity are multifactorial and complex consequences of maladaptive neuronal plasticity after SCI. It is important to distinguish between various symptoms and signs in order to understand the relationship between neuropathic pain and spasticity. Different constellations of pain and spasticity, and injury characteristics (for example, at- and below-level pain, ongoing and evoked pain, shooting and burning pain, spasms and increased muscle tone, complete and incomplete lesions) may reflect different underlying mechanisms. Unraveling the complex constellations, differences, and similarities of these different symptoms and signs is important for increasing our understanding of the intertwined mechanisms. We also need a better understanding of the predictability of outcomes in animal models to model human pain to improve the translation of preclinical trials. These are immense tasks for the future but with significant importance for understanding mechanisms and developing new and differentiated treatments.

\section{DATA ARCHIVING}

There were no data to deposit.

\section{CONFLICT OF INTEREST}

NBF has received honoraria or travel support from Pfizer, Grünenthal, Astellas, Teva Pharmaceuticals, and Novartis Pharma and grants from IMI Europain (EU/EFPIA) outside the submitted work.

1 Brown A, Weaver LC. The dark side of neuroplasticity. Exp Neurol 2012; 235: $133-141$.

2 Widerstrom-Noga EG, Felipe-Cuervo E, Yezierski RP. Chronic pain after spinal injury: Interference with sleep and daily activities. Arch Phys Med Rehabil 2001; 82 1571-1577.

3 Westerkam D, Saunders LL, Krause JS. Association of spasticity and life satisfaction after spinal cord injury. Spinal Cord 2011; 49: 990-994.

4 Lundstrom U, Wahman K, Seiger A, Gray DB, Isaksson G, Lilja M. Participation in activities and secondary health complications among persons aging with traumatic spinal cord injury. Spinal Cord 2016; 55: 367-372.

5 Andresen SR, Biering-Sorensen F, Hagen EM, Nielsen JF, Bach FW, Finnerup NB. Pain, spasticity and quality of life in individuals with traumatic spinal cord injury in Denmark. Spinal Cord 2016; 54: 973-979.

6 Adriaansen JJ, Ruijs LE, van Koppenhagen CF, van Asbeck FW, Snoek GJ, van KD et al. Secondary health conditions and quality of life in persons living with spinal cord injury for at least ten years. J Rehabil Med 2016; 48: 853-860.

7 Rubinelli S, Glassel A, Brach M. From the person's perspective: Perceived problems in functioning among individuals with spinal cord injury in Switzerland. J Rehabil Med 2016; 48: 235-243.

8 Siddall PJ, McClelland JM, Rutkowski SB, Cousins MJ. A longitudinal study of the prevalence and characteristics of pain in the first 5 years following spinal cord injury. Pain 2003; 103: 249-257.

9 Holtz KA, Lipson R, Noonan VK, Kwon BK, Mills PB. The prevalence and effect of problematic spasticity following traumatic spinal cord injury. Arch Phys Med Rehabil 2016; 98: 1132-1138.

10 Finnerup NB, Jensen MP, Norrbrink C, Trok K, Johannesen IL, Jensen TS et al. A prospective study of pain and psychological functioning following traumatic spinal cord injury. Spinal Cord 2016; 51: 816-821.

11 Burke D, Fullen BM, Stokes D, Lennon O. Neuropathic pain prevalence following spinal cord injury: A systematic review and meta-analysis. Eur J Pain 2017; 21: 29-44.

12 Jensen TS, Baron R, Haanpaa M, Kalso E, Loeser JD, Rice AS et al. A new definition of neuropathic pain. Pain 2011; 152: 2204-2205.

13 Finnerup NB, Haroutounian S, Kamerman P, Baron R, Bennett DL, Bouhassira D et al. Neuropathic pain: an updated grading system for research and clinical practice. Pain 2016; 157: 1599-1606.

14 Bryce TN, Biering-Sorensen F, Finnerup NB, Cardenas DD, Defrin R, Lundeberg T et al. International spinal cord injury pain (ISCIP) classification: part I. background and description. Spinal Cord 2012; 50: 413-417.

15 Pandyan AD, Gregoric M, Barnes MP, Wood D, Van WF, Burridge J et al. Spasticity: clinical perceptions, neurological realities and meaningful measurement. Disabil Rehabil 2005; 27: 2-6.

16 Biering-Sorensen F, Burns AS, Curt A, Harvey LA, Jane MM, Nance PW et al. International spinal cord injury musculoskeletal basic data set. Spinal Cord 2012; 50: 797-802.

17 Lance WL"Symposium Synopsis,"in. Spasticity: Disorderd Motor Contro/Feldman RG, Young RR, Koella WPeds. Symposia Specialists INC. MEdical books: Chicago, IL, USA. 1980, 485-494.

18 Nielsen JB, Crone C, Hultborn $\mathrm{H}$. The spinal pathophysiology of spasticity-from a basic science point of view. Acta Physiol 2007; 189: 171-180.

19 Sjolund $\mathrm{BH}$. Pain and rehabilitation after spinal cord injury: the case of sensory spasticity? Brain Res Brain Res Rev 2002; 40: 250-256.

20 Mueller ME, Gruenthal M, Olson WL, Olson WH. Gabapentin for relief of upper motor neuron symptoms in multiple sclerosis. Arch Phys Med Rehabil 1997; 78: 521-524.

21 Braid JJ, Kirker SG, Baguley IJ. Spasticity increases during pregabalin withdrawal. Brain Inj 2013; 27: 120-124.

22 Canavero S, Bonicalzi V. Intravenous subhypnotic propofol in central pain: a doubleblind, placebo-controlled, crossover study. Clin Neuropharmacol 2004; 27: 182-186.

23 Besson M, Matthey A, Daali Y, Poncet A, Vuilleumier P, Curatolo M et al. GABAergic modulation in central sensitization in humans: a randomized placebo-controlled pharmacokinetic-pharmacodynamic study comparing clobazam with clonazepam in healthy volunteers. Pain 2015; 156: 397-404.

24 Finnerup NB, Attal N, Haroutounian S, McNicol E, Baron R, Dworkin RH et al. Pharmacotherapy for neuropathic pain in adults: a systematic review and meta-analysis. Lancet Neurol 2015; 14: 162-173.

25 Cardenas DD, Warms CA, Turner JA, Marshall H, Brooke MM, Loeser JD. Efficacy of amitriptyline for relief of pain in spinal cord injury: results of a randomized controlled trial. Pain 2002; 96: 365-373.

26 Shaikh A, Phadke CP, Ismail F, Boulias C. Relationship between botulinum toxin, spasticity, and pain: a survey of patient perception. Can J Neurol Sci 2016; 43: 311-315. 
27 Priebe MM, Sherwood AM, Thornby JI, Kharas NF, Markowski J. Clinical assessment of spasticity in spinal cord injury: a multidimensional problem. Arch Phys Med Rehabil 1996; 77: 713-716.

28 Biering-Sorensen F, Nielsen JB, Klinge K. Spasticity-assessment: a review. Spinal Cord 2006; 44: 708-722.

29 Attal N, Bouhassira D, Baron R, Dostrovsky J, Dworkin RH, Finnerup N et al. Assessing symptom profiles in neuropathic pain clinical trials: Can it improve outcome? Eur J Pain 2011; 15: 441-443.

30 von Hehn CA, Baron R, Woolf CJ. Deconstructing the neuropathic pain phenotype to reveal neural mechanisms. Neuron 2012; 73: 638-652.

31 Finnerup NB, Norrbrink C, Trok K, Piehl F, Johannesen IL, Sorensen JC et al. Phenotypes and predictors of pain following traumatic spinal cord injury: a prospective study. J Pain 2014; 15: 40-48.

32 Zeilig G, Enosh S, Rubin-Asher D, Lehr B, Defrin R. The nature and course of sensory changes following spinal cord injury: predictive properties and implications on the mechanism of central pain. Brain 2012; 135: 418-430.

33 Bouhassira D, Attal N, Fermanian J, Alchaar H, Gautron M, Masquelier E et al. Development and validation of the Neuropathic Pain Symptom Inventory. Pain 2004; 108: 248-257.

34 Baron R, Maier C, Attal N, Binder A, Bouhassira D, Cruccu G et al. Peripheral Neuropathic Pain: A mechanism-related organizing principle based on sensory profiles. Pain 2017; 158: 261-272.

35 Widerstrom-Noga EG, Finnerup NB, Siddall PJ. Biopsychosocial perspective on a mechanisms-based approach to assessment and treatment of pain following spinal cord injury. J Rehabil Res Dev 2009; 46: 1-12.

36 Widerstrom-Noga E, Felix ER, Adcock JP, Escalona M, Tibbett J. Multidimensional neuropathic pain phenotypes after spinal cord injury. J Neurotrauma 2016; 33: 482-492.

37 Helfert SM, Reimer M, Hoper J, Baron R. Individualized pharmacological treatment of neuropathic pain. Clin Pharmacol Ther 2015; 97: 135-142.

38 Finnerup NB, Sindrup SH, Bach FW, Johannesen IL, Jensen TS. Lamotrigine in spinal cord injury pain: a randomized controlled trial. Pain 2002; 96: 375-383.

39 Demant DT, Lund K, Vollert J, Maier C, Segerdahl M, Finnerup NB et al. The effect of oxcarbazepine in peripheral neuropathic pain depends on pain phenotype: a randomised, double-blind, placebo-controlled phenotype-stratified study. Pain 2014; 155: 2263-2273.

40 Widerstrom-Noga E, Biering-Sorensen F, Bryce TN, Cardenas DD, Finnerup NB, Jensen MP et al. The International Spinal Cord Injury Pain Extended Data Set (Version 1.0). Spinal Cord 2016; 54: 1036-1046.

41 Kramer JL, Minhas NK, Jutzeler CR, Erskine EL, Liu LJ, Ramer MS. Neuropathic pain following traumatic spinal cord injury: Models, measurement, and mechanisms. J Neurosci Res 2016.

42 Percie, du SN, Rice AS. Improving the translation of analgesic drugs to the clinic: animal models of neuropathic pain. Br J Pharmacol 2014; 171: 2951-2963.

43 Davoody L, Quiton RL, Lucas JM, Ji Y, Keller A, Masri R. Conditioned place preference reveals tonic pain in an animal model of central pain. J Pain 2011; 12: 868-874.

44 Wodarski R, Delaney A, Ultenius C, Morland R, Andrews N, Baastrup C et al. Crosscentre replication of suppressed burrowing behaviour as an ethologically relevant pain outcome measure in the rat: a prospective multicentre study. Pain 2016; 157: 2350-2365.

45 Galan-Arriero I, Avila-Martin G, Ferrer-Donato A, Gomez-Soriano J, Bravo-Esteban E, Taylor J. Oral administration of the p38alpha MAPK inhibitor, UR13870, inhibits affective pain behavior after spinal cord injury. Pain 2014; 155: 2188-2198.

46 Baastrup C, Maersk-Moller CC, Nyengaard JR, Jensen TS, Finnerup NB. Spinal-, brainstem- and cerebrally mediated responses at- and below-level of a spinal cord contusion in rats: evaluation of pain-like behavior. Pain 2010; 151: 670-679.

47 Vierck CJ, Yezierski RP. Comparison of operant escape and reflex tests of nociceptive sensitivity. Neurosci Biobehav Rev 2015; 51: 223-242.

48 Vierck CJ, Light AR. in Spinal Cord Injury Pain: Assessment, Mechanisms, Management. Progress in Pain Research and Management. Yezierski RP, Burchiel KJ (eds) IASP Press: Seattle, WA, USA. 2002, 137-154.
49 Yezierski RP, Vierck CJ. Reflex and pain behaviors are not equivalent: lessons from spinal cord injury. Pain 2010; 151: 569-570.

50 van GS, Deumens R, Leerink M, Nguyen S, Joosten EA, Marsala M. Translation of the rat thoracic contusion model; part 1-supraspinally versus spinally mediated pain-like responses and spasticity. Spinal Cord 2014; 52: 524-528.

51 Hsieh JT, Wolfe DL, Miller WC, Curt A. Spasticity outcome measures in spinal cord injury: psychometric properties and clinical utility. Spinal Cord 2008; 46: 86-95.

52 Vierck CJ, Cannon RL, Stevens KA, Acosta-Rua AJ, Wirth ED. in Spinal Cord Injury Pain: Assessment, Mechanisms, Management. Progress in Pain Research and Management. Yezierski RP, Burchiel KJ (eds) IASP Press: Seattle, WA, USA. 2002, 155-173.

53 Ashworth B. Preliminary trial of carisoprodol in multiple sclerosis. Practitioner 1964; 192: 540-542.

54 Bohannon RW, Smith MB. Interrater reliability of a modified Ashworth scale of muscle spasticity. Phys Ther 1987; 67: 206-207.

55 Tardieu G, Shentoub S, Delarue R. [Research on a technic for measurement of spasticity]. Rev Neurol 1954; 91: 143-144.

56 Penn RD, Savoy SM, Corcos D, Latash M, Gottlieb G, Parke B et al. Intrathecal baclofen for severe spinal spasticity. N Engl J Med 1989; 320: 1517-1521.

57 Benz EN, Hornby TG, Bode RK, Scheidt RA, Schmit BD. A physiologically based clinical measure for spastic reflexes in spinal cord injury. Arch Phys Med Rehabil 2005; 86: 52-59.

58 Hiersemenzel LP, Curt A, Dietz V. From spinal shock to spasticity: neuronal adaptations to a spinal cord injury. Neurology 2000; 54: 1574-1582.

59 Eaton M. Common animal models for spasticity and pain. J Rehabil Res Dev 2003; 40: 41-54.

60 Corleto JA, Bravo-Hernandez M, Kamizato K, Kakinohana O, Santucci C, Navarro MR et al. Thoracic 9 spinal transection-induced model of muscle spasticity in the rat: a systematic electrophysiological and histopathological characterization. PLOS ONE 2015; 10: e0144642.

61 Tashiro S, Shinozaki M, Mukaino M, Renault-Mihara F, Toyama Y, Liu M et al. BDNF Induced by Treadmill training contributes to the suppression of spasticity and allodynia after spinal cord injury via upregulation of KCC2. Neurorehabil Neural Repair 2015; 29: 677-689.

62 Marsala M, Hefferan MP, Kakinohana O, Nakamura S, Marsala J, Tomori Z. Measurement of peripheral muscle resistance in rats with chronic ischemia-induced paraplegia or morphine-induced rigidity using a semi-automated computer-controlled muscle resistance meter. J Neurotrauma 2005; 22: 1348-1361.

63 Bennett DJ, Gorassini M, Fouad K, Sanelli L, Han Y, Cheng J. Spasticity in rats with sacral spinal cord injury. J Neurotrauma 1999; 16: 69-84.

64 Gonzenbach RR, Gasser P, Zorner B, Hochreutener E, Dietz V, Schwab ME. Nogo-A antibodies and training reduce muscle spasms in spinal cord-injured rats. Ann Neurol 2010; 68: 48-57.

65 Kathe C, Hutson TH, McMahon SB, Moon LD. Intramuscular Neurotrophin-3 normalizes low threshold spinal reflexes, reduces spasms and improves mobility after bilateral corticospinal tract injury in rats. Elife 2016; 5: e18146.

66 Dietz V, Sinkjaer T. Spasticity. Handb Clin Neurol 2012; 109: 197-211.

67 Colloca L, Ludman T, Bouhassira D, Baron R, Dickenson AH, Yarnitsky D et al. Neuropathic pain. Nat Rev Dis Primers 2017; 3: 17002.

68 Vierck CJ, Light AR. Allodynia and hyperalgesia within dermatomes caudal to a spinal cord injury in primates and rodents. Prog Brain Res 2000; 129: 411-428.

69 Vierck CJJ, Light AR. Effects of combined hemotoxic and anterolateral spinal lesions on nociceptive sensitivity. Pain 1999; 83: 447-457.

70 Finnerup NB, Johannesen IL, Fuglsang-Frederiksen A, Bach FW, Jensen TS. Sensory function in spinal cord injury patients with and without central pain. Brain 2003; 126: 57-70.

71 Finnerup NB, Sorensen L, Biering-Sorensen F, Johannesen IL, Jensen TS. Segmental hypersensitivity and spinothalamic function in spinal cord injury pain. Exp Neurol 2007; 207: 139-149.

72 Levitan Y, Zeilig G, Bondi M, Ringler E, Defrin R. Predicting the Risk for central pain using the sensory components of the international standards for neurological classification of spinal cord injury. J Neurotrauma 2015; 32: 1684-1692. 